\title{
Martensitic transformation in NiTiCo strip covered by nanocrystalline platinum layer
}

\author{
T. Goryczka ${ }^{\text {a1 }}$, J. Lelatko ${ }^{1}$, D. Vokoun ${ }^{2}$, P. Ochin ${ }^{3}$ \\ ${ }^{1}$ University of Silesia, Institute of Materials Science, Bankowa 12, 40-007 Katowice, Poland \\ ${ }^{2}$ Institute of Physics ASCR, v.v.i., Na Slovance 2, 18221Prague, Czech Republic. \\ ${ }^{3}$ ICMPE CNRS- Universite Paris 12 (UMR 7182) 2-8 rue Henri Dunant 94320 Thiais, France
}

\begin{abstract}
The surface modifications and their effects on the transformation characteristics of shape memory alloys are of interest. The NiTiCo strip was produced applying twin roll casting technique and after that covered by platinum layer using magnetron sputtering. Structure of the layer was studied by means of X-ray diffraction and electron microscopy. Transformation temperatures were determined using differential scanning calorimeter (DSC). The investigations show that in the NiTiCo strip occurs two-steps (by the R-phase) reversible martensitic transformation between the parent B2 phase and the monoclinic martensite B19'. The platinum layer reveals nanocrystalline structure with average grain diameter of $41 \mathrm{~nm}$. It was stated that the nanocrystalline platinum layer does not limit martensitic transformation in the covered strip and can be used as a protective layer.
\end{abstract}

\section{Introduction}

NiTi-based shape memory alloys (SMA) have been well known from their practical application, especially, in medicine and biomedical engineering [1, 2]. However, when SMA's used inside of human body, a certain concern about SMA's negative influence is reported [3, 4]. Considering the high nickel content in NiTi alloy, a great attention has been paid to the dissolution of nickel from the base material due to corrosion. In order to prevent dissolution of nickel ions, various surface modification have been proposed. Coatings with nitrides, oxides or carbides seem to be an attractive way to create a barrier, which sufficiently increases corrosion resistance [5-11]. However, too thick and/or stiff layer can limit the occurrence of the martensitic transformation. In consequence, shape memory effect may be deteriorated. Noble metals such as Au and Pt are biocompatible having excellent adherence to a high number of various surfaces. For our surface modification experiments, we chose platinum because of its properties such as flexibility, good corrosion resistance. Both gold and platinum are well known for their medical applications as the implants [12-14]. However, platinum shows better biocompatibility [15] and corrosion resistance [16] as well as enhances radiopacity [17].

The present study is focused on the characterization of structure of the nanocrystalline platinum layer deposited on the $\mathrm{Ni}_{47} \mathrm{Ti}_{50} \mathrm{Co}_{3}$ shape memory strip. The influence of the Pt layer on the SMA's transformation behaviour of the martensitic transformation is discussed.

\section{Experimental data}

A strip, with the nominal composition $\mathrm{Ti}-47$ at $\% \mathrm{Ni}-3$ at.\% $\mathrm{Co}$, was produced applying twin roll casting technique (TRC) [18]. The thickness of the strip was $282 \mu \mathrm{m}$. From the central part of the strip a sample, $15 \mathrm{~mm}$ wide and $70 \mathrm{~mm}$ long, was cut and subjected to the surface modification. Thin platinum layer was deposited, using magnetron sputtering technique, on both the etched surfaces of the strip. The process was performed at a

a e-mail: tomasz.goryczka@us.edu.pl

This is an Open Access article distributed under the terms of the Creative Commons Attribution-Noncommercial License (http://creativecommons.org/licenses/by-nc/3.0/), which permits unrestricted use, distribution, and reproduction in any noncommercial medium, provided the original work is properly cited. 
constant power of $100 \mathrm{~W}$ with the deposition rate $0.5 \mathrm{~nm} / \mathrm{s}$. The sample was mounted at the top of a cooled holder $10 \mathrm{~cm}$ from the Pt target. The holder with the strips was rotating around the normal to the sample surface to improve the coating thickness uniformity. The chamber was filed with high purity argon. Sputtering pressure was 7 mTorr. The platinum layer was $1.45 \pm 0.06 \mu \mathrm{m}$ thick. The Pt thickness was determined as a mean value acquired from 20 measurements using a profilograph MODEL M201.

Structure of the NiTiCo strip covered by the platinum layer was studied using a transmission electron microscope (TEM) JEM-3010, a scanning electron microscope (SEM) JSM-6480 and X-ray diffractometer X'Pert-Pro (Philips). The martensitic transformation behavior was studied applying a differential scanning calorimeter (DSC). The transformation temperatures were determined from the DSC cooling/heating curves registered using a Perkin-Elmer instrument.

\section{Results and discussion}

\subsection{Microstructure of platinum layer}

The main idea of the TRC application for shape memory alloy casting is to obtain a strip in the ready-to-use state. During the casting, first, thin metal layers solidify on the surface of the rolls simultaneously. After that, the remaining liquid is spread from the central part of the gap to its outer side forming the strip. As the crystallization front proceeds from both rolls the columnar grains are developed. Solidification on the wheel surface causes grains formation in two characteristic zones (Fig. 1a). First one (A), containing fine grains, is associated with rolling. Zone B reveals columnar grains growing perpendicularly to the rolling direction. Surface of the as-cast strip containing all these microstructural aspects was perfectly covered by the platinum layer using magnetron sputtering. The results can be seen in Figure $1 \mathrm{~b}$.

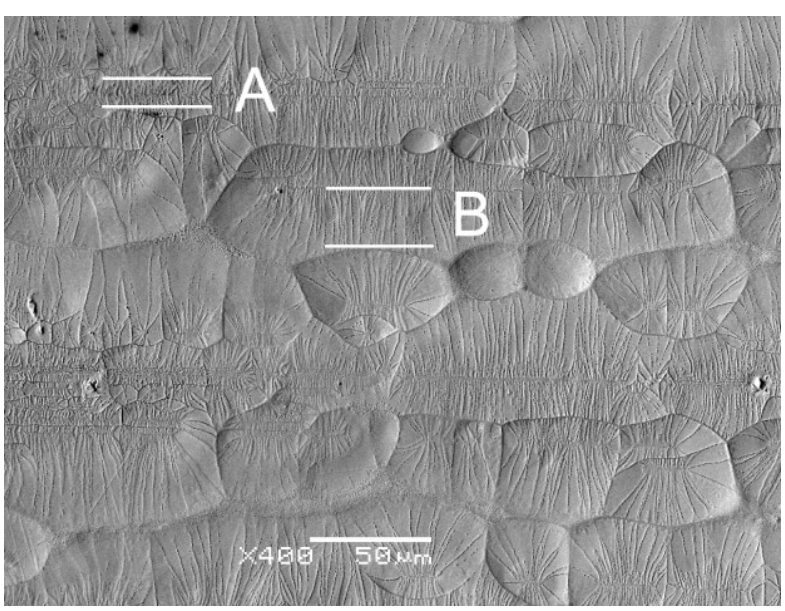

a)

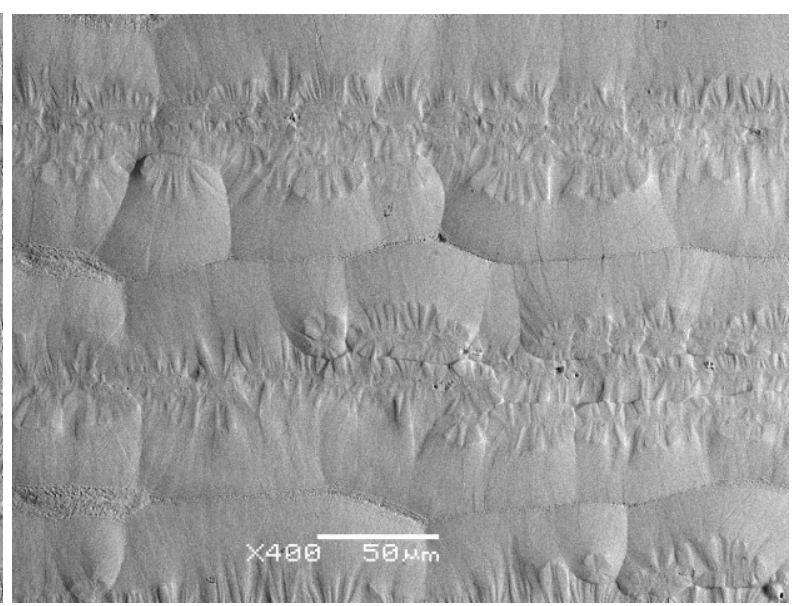

b)

Fig. 1. SEM images of surface: the as-cast strip (a) and after platinum deposition (b)

The presence of platinum layer was confirmed by the X-ray diffraction. Figure 2a shows an X-ray diffraction pattern of the covered strip registered in the classical Bragg-Brentano geometry. Among diffraction lines, which belong to the B2 parent phase, the presence of the strongest platinum line 111 was confirmed. In order to examine the structure (phase composition) of the layer the X-ray diffraction patterns were collected at the incidence angles: $0.3,0.4,0.5,0.6$ and 1 degree using a grazing incidence diffraction technique (GIXD). Figure $2 \mathrm{~b}$ shows an example of the X-ray diffraction pattern registered at the incidence angle $0.5 \mathrm{deg}$. All the diffraction patterns contain diffraction lines characteristic for platinum. Only the $011_{\mathrm{B} 2}$ line was still present in all the diffraction patterns including that one collected at $0.3 \mathrm{deg}$. The X-ray diffraction registered at the incidence angle $0.5 \mathrm{deg}$ was subjected to the Rietveld refinement. The lattice parameter for platinum was calculated using corrections for asymmetrical geometry realized in GIXD technique [19]. It equals to 0.39143 $\mathrm{nm}$. Broadening of full width at half-maximum (FWHM) of diffraction lines observed for the platinum, suggests that the layer was formed from nanocrystalline grains. In order to determine the crystallite size the WilliamsonHall method was applied [20]. Also, lattice distortion was calculated. Diffraction lines were fitted using X'Pert Plus computer program. The instrumental broadening was corrected using the $\mathrm{LaB}_{6}$ standard (NIST SRM 660a). It has been found that the mean size of platinum crystallites equals $36 \mathrm{~nm}$, whereas the lattice distortion was 
relatively low $-0.19 \%$. It leads to decrease of stresses at an interface between the NiTiCo strip and the platinum layer. It is especially important when the covered strip is to be used as a shape memory element.

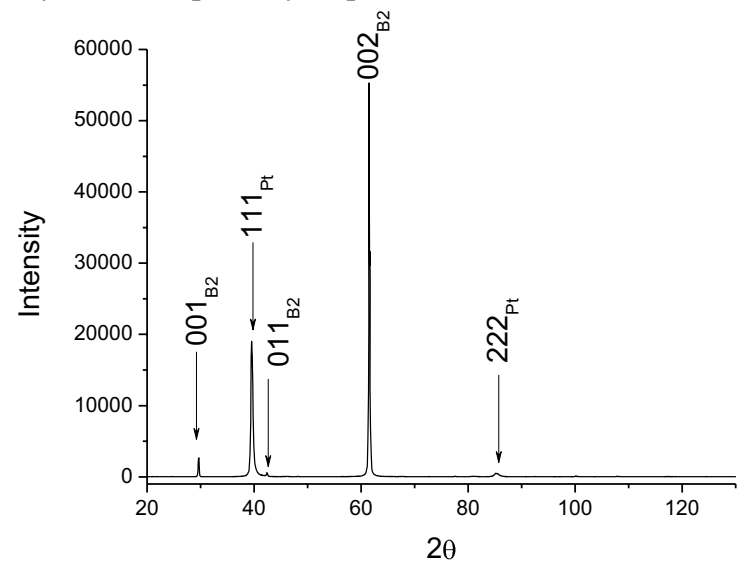

a)

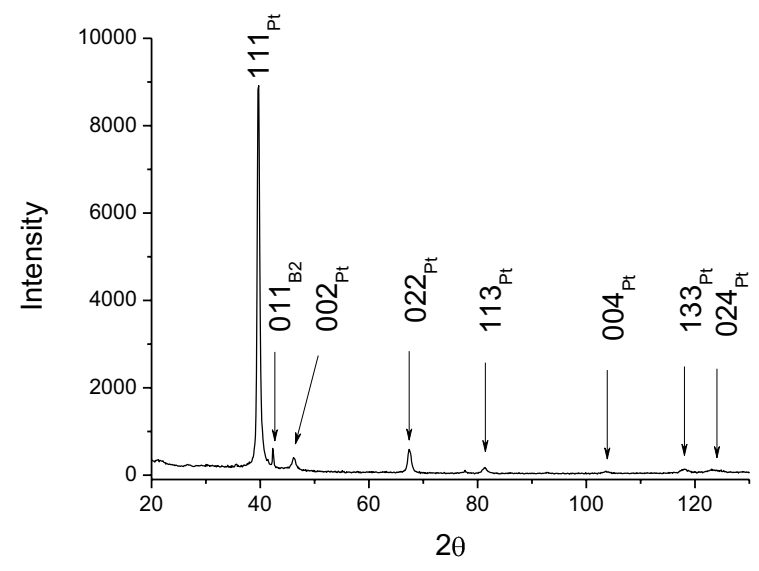

b)

Fig. 2. X-ray diffraction patterns registered for the covered strip in: Bragg-Brentano geometry (a) and GIXD technique at constant incidence angle $0.5 \mathrm{deg}$ (b)

The TEM observations of the layers confirmed the nano-crystalline character of the platinum layer. Figure 3a shows the plain-view of the Pt layer. The electron diffraction pattern (Fig. 3b) reveals, that diffraction spots create rings characteristic for nanocrystalline material. The calculated interplanar distances are consistent with the results obtained from the X-ray diffraction pattern. The mean grain size, determined from TEM images, was $41 \mathrm{~nm}$.

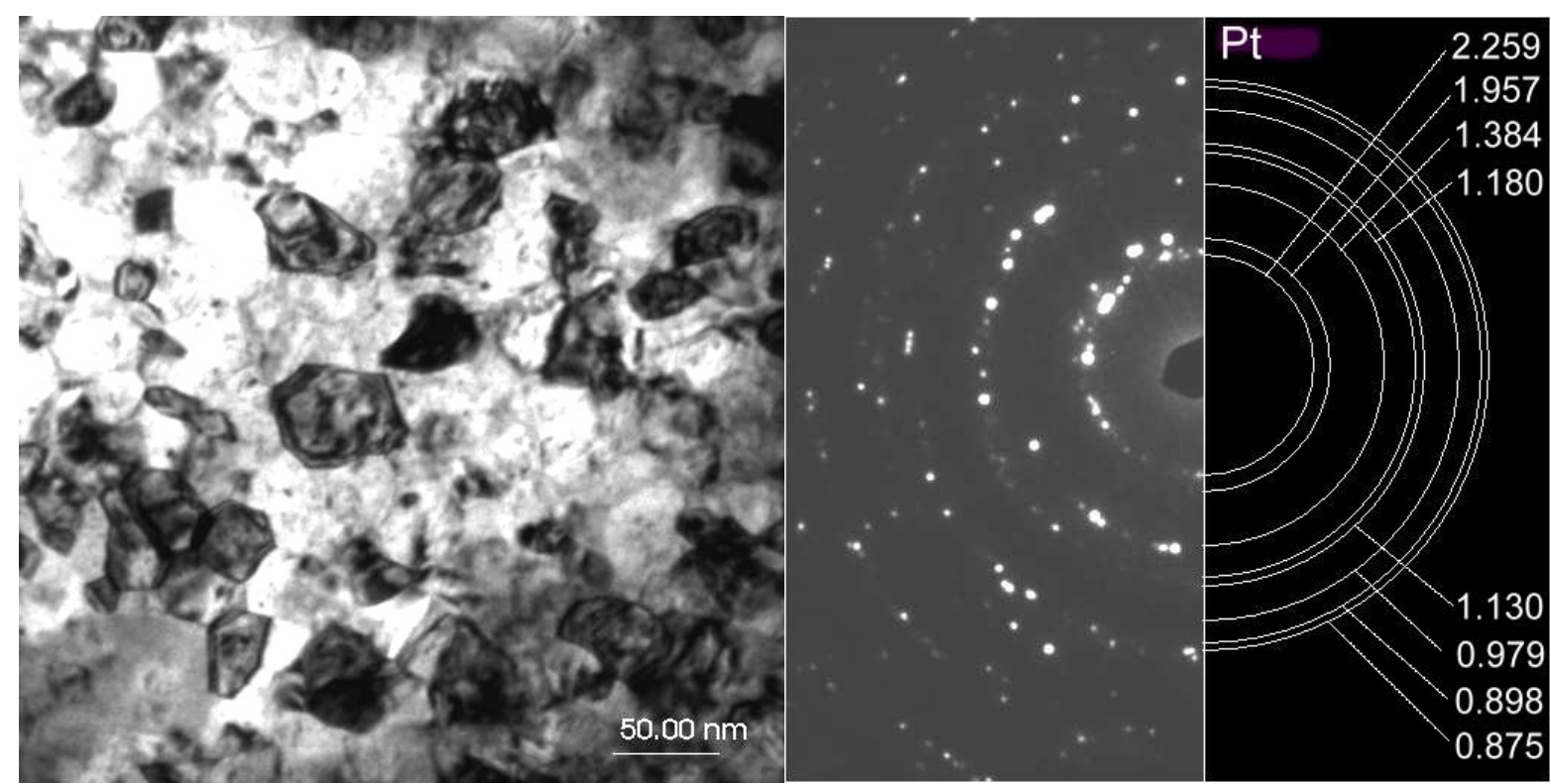

a)

b)

Fig. 3. Plan-view TEM image of platinum layer (a) and electron diffraction pattern (observed/calculated) (b)

\subsection{Martensitic transformation behavior}

In order to study the course of the martensitic transformation in the as-cast strip and the covered one the DSC cooling/heating curves were registered with the rate of $10 \mathrm{~K} / \mathrm{min}$. Figure 4 shows a comparison of the obtained results. Both the samples reveal the reversible martensitic transformation. Three thermal peaks were observed during sample cooling. The first one belongs to the transformation of the B2 parent phase to the R-phase. The further two peaks are evidence of the B19' martensite formed in two stages. In the case of the as-cast strip some 
irregularities were observed in the area of the two-stage martensitic transformation. It can be due to the high structural defect concentration. It was reported in [18] that after several thermal cycles the density of point defects and dislocations decreases. In consequence, martensite stabilizes and the transformation proceeds in one stage. In contrary, cooling curve registered for the covered sample shows a regular shape. It can be explained by a possibility that during sputtering sample temperature rises to a level, which is enough for annealing of point defects as well as a decrease of the dislocations density. On the heating curve only two overlapping thermal peaks are observed for the as-cast strip. The reverse martensitic transformation proceeds from the monoclinic martensite B19' through the R-phase to the B2 parent phase. In the case of the covered sample, one asymmetric broad thermal peak appeared. Both the transformation: $\mathrm{B} 19^{\prime} \rightarrow \mathrm{R}$ and $\mathrm{R} \rightarrow \mathrm{B} 2$ start at comparable temperatures. In order to analyze the influence of the sputtering process on the martensitic transformation the characteristic temperatures of this transition were calculated from DSC curves using the slope extension method. The results are reported in Table 1. The thermal peaks observed during cooling and heating for the covered sample, shift to higher temperature. Comparing the temperatures associated to the $\mathrm{B} 2 \rightarrow \mathrm{R}$ transformation the shift concerns $\mathrm{R}_{\mathrm{s}}$ and does not exceed $4.1 \mathrm{~K}$. Temperature $R_{f}$ is stable at $272 \mathrm{~K}$. Also the temperatures of the forward martensitic transformation $\mathrm{M}_{\mathrm{s}}$ and $\mathrm{M}_{\mathrm{f}}$ are higher in the covered sample by $2.3 \mathrm{~K}$ and $4 \mathrm{~K}$, respectively. In the case of the reverse transformation, $\mathrm{A}_{\mathrm{s}}$ and $\mathrm{A}_{\mathrm{f}}$ temperatures differs by $3.2 \mathrm{~K}$ and $5.8 \mathrm{~K}$, respectively.

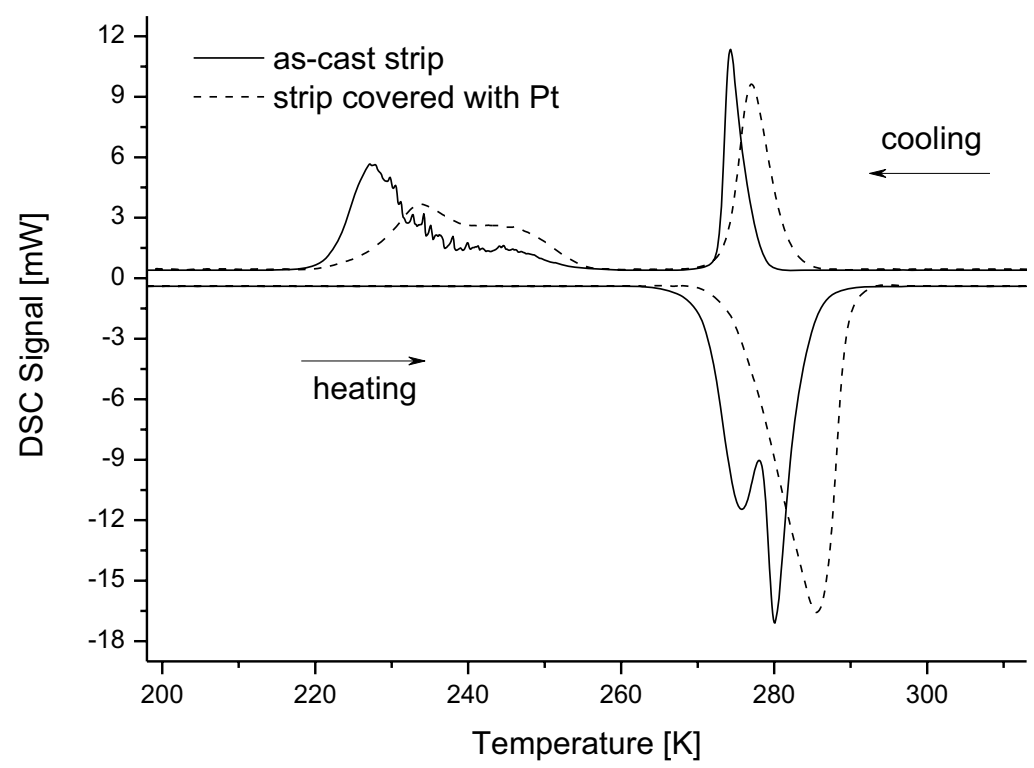

Fig. 4. Comparison of DSC cooling/heating curves for the as-cast strip and covered with platinum layer

If the covered strip is to be used for a shape memory element, it is also worthy to consider the energy, which can be received from the strip during shape recovery. In comparison to the as-cast strip the transformation heat lowers its value in the covered strip. However, the decrease of enthalpy does not exceed $12 \%$ for the reverse as well as for the forward transformation. The source of the relatively high loss of transformation enthalpy is the difference between mass of the samples used for the DSC measurement. The sample mass of the covered strip increased by $8 \%$ due to the presence of the platinum layers. Considering the fact that platinum does not exhibit any martensitic transformation the real loss of transformation enthalpies is lower than $2 \%$.

Table 1. Temperatures and transformation heats of the reversible martensitic transformation

\begin{tabular}{|c|c|c|c|c|c|c|c|c|c|}
\hline Strip & $\begin{array}{c}\mathrm{R}_{\mathrm{S}} \\
{[\mathrm{K}]}\end{array}$ & $\begin{array}{c}\mathrm{R}_{\mathrm{F}} \\
{[\mathrm{K}]}\end{array}$ & $\begin{array}{c}Q^{\mathrm{B} 2 \rightarrow \mathrm{R}} \\
{[\mathrm{J} / \mathrm{g}]}\end{array}$ & $\begin{array}{c}\mathrm{M}_{\mathrm{S}} \\
{[\mathrm{K}]}\end{array}$ & $\begin{array}{c}\mathrm{M}_{\mathrm{F}} \\
{[\mathrm{K}]}\end{array}$ & $\begin{array}{c}Q^{\mathrm{R} \rightarrow \mathrm{B}^{\prime} 9^{\prime}} \\
{[\mathrm{J} / \mathrm{g}]}\end{array}$ & $\begin{array}{c}\mathrm{A}_{\mathrm{S}} \\
{[\mathrm{K}]}\end{array}$ & $\begin{array}{c}\mathrm{A}_{\mathrm{F}} \\
{[\mathrm{K}]}\end{array}$ & $\begin{array}{c}Q^{\mathrm{B} 19^{\prime} \rightarrow \mathrm{B}^{2}} \\
{[\mathrm{~J} / \mathrm{g}]}\end{array}$ \\
\hline As-cast & 277.7 & 272.5 & 7.2 & 253.1 & 221.4 & 14.9 & 271.1 & 283.7 & 22.5 \\
\hline Covered & 281.8 & 272.4 & 6.4 & 255.4 & 225.4 & 13.1 & 274.3 & 289.5 & 19.7 \\
\hline
\end{tabular}

where: $R_{s}$ - start of the R-phase transformation, $R_{f}$ - finish of the R-phase transformation, $M_{s}$ - start of the forward martensitic transformation, $\mathrm{M}_{\mathrm{f}}$ - finish of the forward martensitic transformation, $\mathrm{A}_{\mathrm{s}}-$ start of reverse martensitic transformation, $\mathrm{A}_{\mathrm{f}}$ - finish of the reverse martensitic transformation, $Q$ - transformation heat 


\section{Conclusions}

- The thin platinum layer deposited on $\mathrm{Ni}_{47} \mathrm{Ti}_{50} \mathrm{Co}_{3}$, alloy using magnetron sputtering technique, reveals nanocrystalline structure.

- Deposited platinum layer practically does not limit the reversible martensitic transformation of the $\mathrm{Ni}_{47} \mathrm{Ti}_{50} \mathrm{Co}_{3}$ strips.

- Magnetron sputtering causes a shift of the martensitic transformation temperatures, in $\mathrm{Ni}_{47} \mathrm{Ti}_{50} \mathrm{Co}_{3}$ strip, about 4 degrees in the higher thermal region.

\section{References}

[1] T. Duerig, A. Pelton, D. Stöckel, Mat. Sci. Eng. A 273-275, 149 (1999)

[2] B. O’Briena, W.M. Carroll, M.J. Kelly, Biomat. 23, 1739 (2002)

[3] M.H. Wong, F.T. Cheng, H.C. Man, Applied Surface Science 253, 7527 (2007)

[4] D. Stoeckel, A. Pelton, T. Duerig, Eur. Radiol. 14, 292 (2004)

[5] C. Liu, D. Hu, J. Xu, D. Yang, M. Qi, Mat. Sci. Eng. A 438-440, 879 (2006)

[6] H. Morawiec, J. Lelątko, A. Winiarski, G. Stergioudis, T. Goryczka, P. Pączkowski, Biomat. Eng. 7, 33 (2004)

[7] C. Trépanier, M. Tabrizian, L'H. Yahia, L. Bilodeau, D.L. Piron, J. Biomed. Mater. Res. 43, 433 (1998)

[8] D. Starosvetsky, I. Gotman, Surf. Coat. Technol. 148, 268 (2001)

[9] Z.D. Cui, H.C. Man, X.J. Yang, Appl. Surf. Sci. 208/209, 388 (2003)

[10] Y. Cheng, Y.F. Zheng, Surf. Coat. Technol. 200, 4543 (2006)

[11] H.C. Jiang, L.J. Rong, Surf. Coat. Technol. 201, 1017 (2006)

[12] N. Turner, M. Armitage, R. Butler, G. Ireland, Cell Biol. Internat. 28, 541 (2004)

[13] W.E. Hitselberger, D.E. Brackmann, J.D. Day, R. Shannon, S. Otto, S. Ghosh, Operat. Tech. Neurosurg. 4, 47 (2001)

[14] D.M. Shafer, K. Rogerson, L. Norton, J. Bennett, J. Oral Maxillofac Surg. 53, 1063 (1995)

[15] A. Mohr, Ophthalm. 94, 600 (1997)

[16] E.Y.L. Yiu, D.T.S. Fang, F.C.S. Chu, T.W. Chow, J. Dent. 32, 423 (2004)

[17] C.H. Craig, C.M. Friend, M.R. Edwards, L.A. Cornish, N.A. Gokcen, J. Alloy. Comp. 361, 187 (2003)

[18] T. Goryczka, Mat. Sci. Eng. A 481-482, 676 (2008)

[19] T. Goryczka, G. Dercz, L. Pająk, E. Łagiewka, Solid State Phe. 130, 281 (2007)

[20] G.K. Williamson and W.H. Hall, Acta Metall. 1, 22 (1953) 